\title{
Çuha Çiçeği (Oenothera biennis) ve Tatlı Badem (Prunus dulcis Mill) Yağlarının Anti-enzim Aktivitelerinin Araştırılması
}

\author{
Ebru AKKEMİK ${ }^{1,2 *}$ \\ ${ }^{1}$ Siirt Üniversitesi, Mühendislik Fakültesi, Gıda Mühendisliği Bölümü, Siirt, Türkiye (ORCID: 0000-0002-4177-4884) \\ ${ }^{2}$ Siirt Üniversitesi, Bilim ve Teknoloji Uygulama ve Araştırma Merkezi, Siirt, Türkiye (ORCID: 0000-0002-4177-4884)
}

(İlk Geliş Tarihi 14 Şubat 2020 ve Kabul Tarihi 20 Mart 2020)

(DOI: 10.31590/ejosat.689490)

\begin{abstract}
ATIF/REFERENCE: Akkemik, E (2020). Çuha Çiçeği (Oenothera biennis) ve Tatlı Badem (Prunus dulcis Mill.) Yağlarının Antienzim Aktivitelerinin Araştırılması. Avrupa Bilim ve Teknoloji Dergisi, (18), 583-590.
\end{abstract}

$\ddot{\mathbf{O} z}$

Çalışmamızda iki farklı enzim aktivitesi üzerine Çuha çiçeği (Oenothera biennis) ile tatlı badem (Prunus dulcis Mill.) yağlarının etkileri ne olabilecek sorusu cevaplanmak istendi. Kullandığımız ilk enzim canlılarda $\mathrm{CO}_{2}{ }^{\prime}$ in hidratasyonu ve $\mathrm{HCO}_{3}{ }^{-'}$ 'n dehidratasyonunu dönüşümlü olarak katalizleyerek, hücre içi bikarbonat tampon sistemini oluşturarak, birçok fizyolojik olayda oldukça önemli rol alan karbonik anhidraz I-II izoenzimleridir. İkinci enzim ise asetilkolin molekülünün ayrışmasını katalizleyen, kas hücresi ve sinir arasındaki sinapsta yer alan asetilkolinesteraz enzimidir. Her iki enzimin inhibitörleri, ilaç olma potansiyeli taşımaktadır. Bu nedenle belirtilen yağların inhibisyon etkisi araştırıldı. Bu amaçla ilk olarak karbonik anhidraz I-II izoenzimi sefaroz-4B-L-tirosin-sülfanilamid afinite kolonu ile saflaştırıldı. Ardından en az beș farklı inhibitör konsantrasyonunda enzim aktivitesi bakılarak Çuha çiçeği (Oenothera biennis) ve tatlı badem (Prunus dulcis Mill.) yağlarının enzim aktiviteleri üzerindeki etkileri araştırıldı. Son olarak \%aktivite-[I] grafiği çizilerek Çuha çiçeği (Oenothera biennis) ve tatlı badem (Prunus dulcis Mill.) yağlarının $\mathrm{IC}_{50}$ değerleri tespit edildi. İnsan eritrositlerinden karbonik anhidraz I izoenzimi \%20,12 verimle 119 kat saflaştırılırken, karbonik anhidraz II izoenzimi \% 83,05 verimle 535,72 kat saflaştırıldı. Çuha çiçeği (Oenothera biennis) yağının karbonik anhidraz I-II ve asetilkolinesteraz enzim aktivitesi üzerindeki $\mathrm{IC}_{50}$ değerleri sırasıyla 0,1950, 0,1406 ve $0,1097 \mathrm{mg} / \mathrm{mL}$ olarak, tatlı badem (Prunus dulcis Mill.) yağının karbonik anhidraz I-II ve asetilkolin esteraz enzim aktivitesi üzerindeki $\mathrm{IC}_{50}$ değerleri ise sirasıyla $0,0345,0,0266$ ve $0,0394 \mathrm{mg} / \mathrm{mL}$ olarak tespit edildi. Çalışmada kullanılan her iki yağ karşılaştıııldığında, tatlı badem (Prunus dulcis Millı.) yağının her iki enzim aktivitesi üzerinde daha etkili olduğunu görülmektedir. Bu nedenle sentetik ilaçlar yerine tatı badem (Prunus dulcis Mill.) yağının söz konusu enzimlerin sebep olduğu hastalıkların tedavisinde takviye ilaç olarak kullanılabileceği düşünülmektedir.

\section{Investigation of Anti-enzyme Activities of Primrose (Oenothera biennis) and Sweet Almond (Prunus dulcis Mill.) Oils}

\begin{abstract}
In our study, the question of what might be the effects of Primrose (Oenothera biennis) and sweet almond (Prunus dulcis Mill.) oils on two different enzyme activities was asked. The first enzyme in our study is carbonic anhydrase I-II isoenzymes that play a very important role in many physiological events, by transforming catalysis of $\mathrm{CO}_{2}$ hydration and $\mathrm{HCO}_{3}{ }^{-}$dehydration in living things, by creating an intracellular bicarbonate buffer system. The second enzyme, the acetylcholinesterase enzyme, which was located in the synapse between the muscle cell and nerve, catalyzes the decomposition of the acetylcholine molecule. Inhibitors of both enzymes have the potential to be drugs. Therefore, the inhibition effect of the specified oils was investigated. For this purpose, the first carbonic anhydrase I-II isoenzyme was purified by the sepharose-4B-L tyrosine-sulfonamide affinity column. Then, by looking at enzyme activity in at least
\end{abstract}

* Sorumlu Yazar: Siirt Üniversitesi, Mühendislik Fakültesi, Gıda Mühendisliği Bölümü, Siirt, Türkiye, ORCID: 0000-0002-4177-4884 eakkemik@siirt.edu.tr 
five different inhibitor concentrations, effects of evening primrose (Oenothera biennis) and sweet almond (Prunus dulcis Mill.) oils on enzyme activities were investigated. Finally, $\mathrm{IC}_{50}$ values of Primrose (Oenothera biennis) and sweet almond (Prunus dulcis Mill.) oils were determined by drawing activity\%-[I] graph. Carbonic anhydrase I isoenzyme was purified from human erythrocytes 119 times in $20.12 \%$ yield, while carbonic anhydrase II isoenzyme was purified 535.72 times in $83.05 \%$ yield. IC $_{50}$ values of the primrose oils (Oenothera biennis) on carbonic anhydrase I-II and acetylcholinesterase enzyme activity were 0,1950, 0,1406 and 0,1097 mg / mL, respectively. $\mathrm{IC}_{50}$ values of the sweet almond oil (Prunus dulcis Mill.) on carbonic anhydrase I-II and acetylcholine esterase enzyme activity were $0.0345,0.0266$ and $0.0394 \mathrm{mg} / \mathrm{mL}$ respectively. When both oils used in the study are compared, we see that sweet almond oil (Prunus dulcis Mill.) is more effective on both enzyme activities. Therefore, instead of synthetic drugs, sweet almond (Prunus dulcis Mill.) oil is thought may be used as a supplement in the treatment of diseases caused by the enzymes in question.

Keywords: Acetylcholinesterase, carbonic anhydrase, inhibition, in vitro

\section{Giriş}

Tüm kısımları yenebilen Çuha çiçeği (Oenothera biennis), Onagraceae familyasına ait otuzun üzerinde ülkede ticari üretimi yapılan bir bitkidir (NTP, 2009; Kaya, 2010). Sadece geceleri çiçek açan Çuha çiçeği, gecesefası, yabani gecesefası, kır çuha çiçeği, ateş bitkisi, gece yakı otu, kralların panzehiri ve geniş çan çiçeği isimleri ile de bilinir (Jennifer ve ark., 2001; Kaya, 2010). Bitki kadar bitkiden elde edilen yağıda değerlidir. Soğuk pres, çözücü ekstraksiyonu veya süperkritik karbondioksit ekstraksiyonu yöntemleri kullanılarak elde edilen Çuha çiçeği yağının üretiminde Çin başı çekmektedir (Favati ve King 1991; Jennifer ve ark., 2001; Kaya, 2010). Çuha çiçeği yağı gama linoleik asit (Jennifer ve ark., 2001; Birch ve ark., 2001; NTP, 2009; Kaya, 2010,) içeren antioksidan, antienflamatuar, antikoagülan ve immünomodülatör bir yağdır (Jennifer ve ark., 2001; Birchve ark., 2001; Ismail ve ark., 2008; Riaz ve ark., 2009; Kaya, 2010). Öksürük, astım, romatoid artrit ve deri hastalıklarında da kullanıldığı belirtilmiştir (Hederos ve Berg, 1996; Ammar ve ark 2000). Gıda endüstrisinde başta kuruyemiş olarak tüketilmesinin yanında farklı kullanım alanları da bulan tatlı badem ise (Prunus dulcis Mill.) Rosaceae familyasının Prunoideae alt familyasında yer alan bir meyve türüdür (Akalın, 1952; Bayrak ve Y1lmaz, 2009). Soğuk pres, çözücü ekstraksiyonu veya süperkritik ekstraksiyon gibi farklı yöntemler ile elde edilen yağı en az meyvesi kadar faydalıdır (Ronceroa ve ark., 2016). Orjinine göre değişmekle birlikte tatlı bademin yaklaşık \%50 oranında yağ içerdiği ve bu yağın omega-9 ve omega 6 yăg asitleri bakımından zengin olduğu ifade edilmiştir (Balta, 2013; Ronceroa ve ark., 2016). Badem yağının dermatolojik (Sultana ve ark., 2007; Ahmad, 2010), anti-enflamatuar, anti-hepatotoksisite ve anti-kanser (Davis ve Iwahashi 2001; Zohary ve Hopf 2001; Hyson ve ark., 2002; Jenkins ve ark., 2002; Sultana ve ark., 2007; Ahmad, 2010) etkilerinin olduğu ifade edilmiştir. Ayrıca kolesterolü düşürdüğü ve kardiyovasküler hastalıklarda da etkili olduğu belirtilmiştir (Spiller ve ark., 1998; Chen ve ark., 2006; Jenkins ve ark., 2006). Yapılan literatür çalışmaları neticesinde Çuha çiçeği (Oenothera biennis) ile tatlı badem (Prunus dulcis Mill.) yağlarının karbonik anhidraz I-II ve asetilkolin esteraz enzim aktiviteleri üzerindeki etkilerinin araştırılmadığı tespit edilmiştir. Bu nedenle iki farklı yağ örneğinin çeşitli hastalıklar ile bağlantılı olan karbonik anhidraz I-II ve asetilkolin esteraz enzim aktiviteleri üzerindeki etkilerinin ne olabileceği sorusu bu çalışmada cevaplanmak istenmiştir.

Ökaryot ve prokaryotlarda görülen, birbirinden bağımsız yedi farklı gen ailesi tarafından kodlanan karbonik anhidraz (CA, E.C.4.2.1.1) enzimi bir metalo enzimdir (Gul ve ark., 2017a; Vullo ve ark 2017; Kocyigit ve ark., 2019). İnsanda sadece aktif merkezinde $\mathrm{Zn}^{2+}$ iyonu bulunduran $\alpha$-CAs bulunmaktadır (Gul ve ark., 2017b; Topal ve ark., 2017; Kocyigit ve ark., 2019). Bazı CA izoformları insan vücudunda birçok kritik noktadaki fizyolojik olaylarda etkin rol oynarlar (Kocyigit ve ark., 2019). Metabolizmada görev alan enzimlerin, daha fazla ya da daha az aktiviteye sahip olması farklı metabolik yolaklarda çeşitli problemlere yol açmaktadır (Bıçakçı, 2015). Benzer şekilde enzimlerin normalde bulunmaları gereken hücrelerin dışında farklı bir dokuda olmaları veya daha fazla ya da az eksprese olmaları halinde çeşitli hastalıkların oluştuğu anlaşılamaktadır (Özaslan ve Sivri, 1998). Bu nedenle CA izoenziminin inhibisyonu veya aktivasyonu oldukça önemlidir. Hatta hCA izoenzimlerinin inhibitörlerinin epilepsi, glukoma ve ödemin yanı sıra son dönemde oldukça problem olan obezite ve kanser tedavisinde de kullanılabileceği belirtilmektedir (Boztaş M ve ark., 2015; Taslimi ve ark., 2016a; Akıncıoğlu ve ark., 2015; Gülçin ve ark., 2016; Göksu ve ark., 2016). Bugün literatürde bilinen CA inhibitörleri, sülfonamidler, asetazolamidler, dorzolamidler, metazolamidler ve brinzolamidlerdir (Supuran, 2007; Krasavin ve ark., 2016; Gokcen ve ark., 2017). Ancak bu inhibitörler sentetik kimyasallardır ve birçok yan etkiye sahiptirler (Smirnovienè ve ark., 2017; Kocyigit ve ark., 2019) bu nedenle CA izoenzimlerinin yeni inhibitörleri aranmaya devam etmektedir. Çalışma konusu olan diğer enzimimiz ise Asetilkolinesteraz (AChE, E.C.3.1.1.7) enzimidir. Kas hücresi ve sinir arasındaki sinapsta yer alan AChE, asetilkolin molekülünün (ACh) hidrolizinden sorumludur (Darvesh ve ark., 2008). Çoğunlukla yaşlı insanlarda görülen neurodegenerative bir hastalık olan (Tarawneh ve Holtzman, 2012; Habtemariam, 2019) Alzheimer hastalığında (AH), beyin ve hipokampus kortekslerinde ACh seviyesi azalmaktadır (Akıncıoğlu ve ark., 2014). AChE enzimi AH ile olan ilişkisi nedeniyle bugün birçok araştırmanın konusu olmuştur (Aksu ve ark., 2016). AH ilaçlarının AChE enzim aktivitesi üzerinde inhibisyon etkisi göstermesi, (Aksu ve ark., 2016) etkili bir tedavi için AChE enziminin inhibitörlerinin araştırılmasına sebep olmuştur (Taslimi ve ark., 2016b). Donepezil, rivastigmine ve galantamin AH tedavisinde kullanılan AChE enziminin inhibitörleridir. Ancak bazı hastalarda sınırlı yararlarının olmasının yanı sıra birçokta yan etkiye sahip oldukları ifade edilmiştir (Habtemariam, 2019). AChE doğal inhibitörü olarak farklı ailelerden çeşitli bitki türleri çalışılmıştır, başta kardelen olmak üzere Nergisgiller (Amaryllidaceae), Lycopodiaceae ve Kuzukulağıgiller (Polygonaceae) en çok çalışılan bitki grubudur (Santos ve ark., 2018).

Doğal ürünlerin sentetik ürünler yerine giderek tercih edildiği de yadsınamaz bir gerçektir. Bir kimyasalı sentezlemek hem pahalı hem de uzun bir süreç gerektirmektedir. Bu nedenle doğal ürünlerin enzimler üzerindeki etkileri araştırılarak etkili konsantrasyonu belirlenerek fitoterapi kapsamında hastalıkların tedavisinde kullanılmalıdır. Çalışmamız kapsamında Çuha çiçeği (Oenothera biennis) ile tatlı badem (Prunus dulcis Mill.) yağlarının hCA I-II ve AChE enzimleri üzerindeki etkileri ilk kez araştırılmıştır. 


\section{Materyal ve Metot}

\subsection{Kullanılan Kimyasallar}

Sefaroz-4B, sülfanilamid,Tris, $\mathrm{Na}_{2} \mathrm{SO}_{4}, \mathrm{NaCl}, \mathrm{Na}_{2} \mathrm{HPO}_{4}, \mathrm{NaCH}_{3} \mathrm{COO}, \mathrm{NaClO}_{4}$, p-nitrofenil asetat, etilendiamin tetra-asetik asit (EDTA), asetilkolin iyodat, 5,5'-ditiobis (2-nitrobenzoik asit), sodyum sitrat ve Asetilkolinesteraz; Sgma-Aldrich Chemie GmbH İhracat Departmanı Eschenstrasse 5, 82024 Taufkirchen, Almanya'dan, Çuha çiçeği (Oenothera biennis) ve tatlı badem (Prunus dulcis Mill.) yağı; yerel pazarlardan, L-tirosin; Merck’ten KGaA Frankfurter strasse 250, D-64293 Darmstadt Germany, çalışmada kullanılan diğer kimyasallar ve çözücüler Merck (KGaA Frankfurter strasse 250, D-64293 Darmstadt Germany) ya da Sgma-Aldrich (Chemie GmbH İhracat Departmanı Eschenstrasse 5, 82024 Taufkirchen, Almanya)'den temin edilmiştir.

\subsection{Metot}

\subsubsection{Yăg Ekstrelerinin Hazırlanması}

Çuha çiçeği (Oenothera biennis) ile tatlı badem (Prunus dulcis Mill.) yağlarının stok çözelti $1 \mathrm{mg} / \mathrm{mL}$ olacak şekilde \%96’lık Etanolde seyreltildi. Çalışma sırasında kullanılan seyreltmeler için saf su kullanıldı. (Akkemik ve ark., 2017).

\subsubsection{Insan Eritrosit Karbonik Anhidraz İoenzimlerinin Saflaştırılması}

İlk olarak insan eritrosit çözeltisinden $10 \mathrm{~mL}$ alınarak beş katı kadar buzlu su ile hemoliz olması sağlandı. Hemoliz olan çözelti $4^{\circ} C^{\prime}$ 'de 10.000 xG'de 60 dakika santrifüj (Thermo Scıentıfic/Megafuge 16R) edilerek çökelek atıldı (Akkemik ve ark., 2017; Akkemik ve ark., 2018). Süpernatant saflaştırma işleminde kullanılıncaya kadar $4^{\circ} \mathrm{C}$ 'de saklandı. Hemolizatın pH'sı katı Tris ile 8,7 ayarlandı (Akkemik ve ark., 2017; Adem ve ark., 2019). Ardından elde edilen hemolizat önceden dengelenen (dengeleme tamponu: 25 mM Tris$\mathrm{HCl} / 100 \mathrm{mM} \mathrm{Na} 2 \mathrm{SO}_{4}$ (pH: 8.7)) sefaroz-4B-L-tirosin-sülfanilamid afinite kolonuna yüklendi. Kolon safsızlıkları uzaklaştırmak için (yıkama tamponu: $25 \mathrm{mM}$ Tris- $\mathrm{HCl} / 22 \mathrm{mM} \mathrm{Na}_{2} \mathrm{SO}_{4}(\mathrm{pH} 8.7)$ ) yıkama tamponu ile 280 nm'deki absorbans farkı 0,05 oluncaya kadar yıkand. Son olarak karbonik anhidraz I ve II izoenzileri (hCA I için; $1.0 \mathrm{M} \mathrm{NaCl} / 25 \mathrm{mM} \mathrm{Na}_{2} \mathrm{HPO}_{4}$ (pH 6,3) hCA II için; 0,1 M $\mathrm{NaCH}_{3} \mathrm{COO} / 0,5 \mathrm{M} \mathrm{NaClO}_{4}$ (pH 5.6)) elüsyon tamponları ile elüe edildi (Akkemik ve ark., 2017; Akkemik ve ark., 2019). Saflaştırılan hCA I ve hCA II izoenzimleri ayrı ayrı 50 mM Tris-SO 4 (pH 7,4) tamponuna karşı 24 saat diyaliz edildi (Akkemik ve ark., 2017). Enzim saflığı SDS-PAGE (Laemmli, 1970) ile protein miktarı Bradford (Bradford, 1976) yöntemi ile kontrol edildi.

\subsection{3. hCA I-II İoenzimlerinin Aktivitesinin Belirlenmesi}

Enzim aktivitesi 348 nm'de spektrofotometrik (Shimadzu UV-1280 Spektrofotometresi) olarak belirlendi. Bu yöntemde substrat olarak p-nitrofenil asetat kullanılmaktadır (Verpoorte ve ark., 1967).

\subsubsection{Insan Eritrosit Asetilkolin Esteraz Enziminin Aktivitesinin Belirlenmesi}

AChE'nin aktivitesinin belirlenmesinde spektrofotometrik yöntem olan Ellman ve ark., (1961) yöntemi kullanıldı. Bu yöntemde asetilkolin iyodat substrat olarak kullanıldı. Küvet içi konsantrasyonları 0,1 M Tris-HCl, 0,5 mM EDTA pH:8,0, 0,5 mM asetilkolin iyodat, 0,025 mM 5,5'-ditiobis (2-nitrobenzoik asit), \%0,05 sodyum sitrat olacak şekilde hazırlanan çözeltiye 5,32x10 ${ }^{-3}$ U asetilkolinesteraz enzimi ilave edilerek $412 \mathrm{~nm}$ de absorbans ölçüldü (Polat ve ark., 2015; Kocyiğit ve ark., 2019).

\subsubsection{Inhibison Çalıșması}

İnsan eritrosit CA-I, CA-II izoenzimlerinin ve AChE enziminin aktiviteleri üzerine Çuha çiçeği (Oenothera biennis) ile tatlı badem (Prunus dulcis Mill.) yağlarının etkileri in vitro şartlarda araştırıldı. Çuha çiçeği (Oenothera biennis) ile tatlı badem (Prunus dulcis Mill.) yağlarının her birinin beş farklı konsantrasyonunda enzim aktivitesi bakıldı (Ellman ve ark., 1961; Verpoorte ve ark., 1967). Yă̆ içermeyen aktivite ölçümü kontrol olarak kabul edildi (\%100 aktivite). Çuha çiçeği (Oenothera biennis) ile tatlı badem (Prunus dulcis Mill.) yağların konsantrasyonlarına karşı \%aktivite grafiği çizildi. Elde edilen grafikten $\mathrm{IC}_{50}$ değerleri tespit edildi (Ellman ve ark., 1961; Verpoorte ve ark., 1967; Akkemik ve ark., 2017; Kocyiğit ve ark., 2019).

\section{Araştırma Sonuçları ve Tartışma}

Canlı organizmalardaki pH düzenleme rolleri ile ana tanpon sistemini oluşturan CA'lar birçok biyosentetik reaksiyonda görev almaktadırlar (Scozzafava et al., 2006; Supuran, 2008). Dahası bu enzimler hastalık belirteci veya hastalık faktörü olarak karşımıza çıkmaktadır (Scozzafava et al., 2006; Supuran, 2008; Aggarwal, 2013; Akkemik et al., 2018). Bu nedenle memelilerde 16 izoenzimi bulunan CA'ların inhibitörleri glukoma, epilepsi, kanser, gastrit ve nörolojik hastalıklar gibi çeşitli hastalıkların tedavisinde kullanılmaktadır (Scozzafava et al., 2006; Supuran, 2008; Aggarwal et al., 2013). Bunun sonucu olarakta birçok araştırmacı CA'ların inhibitörlerini veya aktivatörlerini sentezlemektedir. Ancak bir kimyasalın ilaç olarak sentezlemesi için klinik öncesi ve sonrası çalışmaların tamamlanması, insan denekler üzerinde çalışmaların pozitif sonuçlar vermesi gerekmektedir. Bu süreç hem maddi kayıba hemde çok zaman harcamaya sebep olmaktadır (Anonim, 2020). Bu nedenle birçok araştırmacı doğal ürünlerin ilaç olarak değerlendirilebilmesi için sentez yerine etken madde izolasyonu, ya da direk olarak bitki ekstrelerinin sekonder metabolitleri sayesindeki farmakolojik etkilerini tespit etmeye çalışmışlardır (Bangou ve ark. 2011; Gülçin ve ark., 2016; Adem ve ark., 2019; Akkemik ve ark., 2019). Bu çalışmada ise çuha çiçeği (Oenothera biennis) ile tatlı badem (Prunus dulcis Mill.) yağlarının hCA I ve 
hCA II enzim aktivitesi üzerindeki etkileri in vitro şartlarda araştırıldı. Bu amaçla ilk olarak insan eritrositlerinden hCA I izoenzimi \%20,12 verimle 119 kat saflaştırılırken hCA II izoenzimi \%83,05 verimle 535,72 kat saflaştırıldı (Tablo 1). Enzimin saflaştırıldığı SDSPAGE ile kontrol edildi. Karbonik anhidraz izoenzimleri daha önce ekibimiz tarafindan birçok kez saflaştırılmıştır (Akkemik ve ark., 2017; Akkemik ve ark., 2018; Adem ve ark., 2019).

Tablo 1. Karbonik Anhidraz I ve II İzoenzimlerinin Saflaştırma Tablosu

\begin{tabular}{ccccccccc}
\hline $\begin{array}{c}\text { Saflaştırma } \\
\text { Basamakları }\end{array}$ & $\begin{array}{c}\text { Aktivite } \\
(\mathbf{E U ̈ \mathbf { U }} / \mathbf{m L})\end{array}$ & $\begin{array}{c}\text { Protein Miktarı } \\
(\mathbf{m g} / \mathbf{m L})\end{array}$ & $\begin{array}{c}\text { Hacim } \\
(\mathbf{m L})\end{array}$ & $\begin{array}{c}\text { Toplam } \\
\text { Aktivite (EÜ) }\end{array}$ & $\begin{array}{c}\text { Toplam } \\
\text { Protein }(\mathbf{m g})\end{array}$ & $\begin{array}{c}\text { Spesifik Aktivite } \\
\text { (EÜ/mg) }\end{array}$ & $\begin{array}{c}\text { Saflaștırma } \\
\text { Katsayısı }\end{array}$ & $\begin{array}{c}\text { \% } \\
\text { Verim }\end{array}$ \\
\hline Hemolizat & 0,00273 & 44540,98 & 40 & 0,1093 & 1781639,3 & $6,13667 \mathrm{E}-08$ & 1 & 100 \\
hCA I & 0,0022 & 300,984 & 10 & 0,0220 & 3009,8361 & $7,30937 \mathrm{E}-06$ & 119,110 & 20,12 \\
hCA II & 0,01513 & 460,328 & 6 & 0,0908 & 2761,9672 & $3,28751 \mathrm{E}-05$ & 535,72 & 83,05 \\
\hline
\end{tabular}

İnsan eritrositlerinden saflaştırılan hCA I-II ve asetilkolinesteraz enzimlerinin aktivitesi üzerine çuha çiçeği ve tatlı badem yağlarının in vitro şartlarda inhibisyon etkisi gösterdiği tespit edildi (Şekil 1, Tablo 2). Tatlı badem yağının hCA II enzim aktivitesi üzerinde en yüksek inhibisyon etkisini gösterdiği $\left(\mathrm{IC}_{50} 0,0266 \mathrm{mg} / \mathrm{mL}\right)$ genel olarakta çalışılan her iki enzim üzerinde tatlı badem yağının daha etkili olduğu tespit edildi. Çuha çiçeği yağının karbonik anhidraz izoenzimleri ve AChE enzimi üzerindeki etkileri karşılaştıııldı̆̆ında $\mathrm{AChE}$ enzimi üzerinde ( $\mathrm{IC}_{50} 0,1097 \mathrm{mg} / \mathrm{mL}$ ) daha etkili olduğu tespit edildi (Şekil 1, Tablo 2).

Tablo 2. Çuha Çiçeği ve Tatlı Badem Yağının Anti-enzim Aktivitesi

\begin{tabular}{lcccccc}
\hline Inhibitör Madde & \multicolumn{7}{c}{ IC $_{50}(\mathbf{m g} / \mathbf{m L})$} \\
\cline { 2 - 7 } & hCA-I & $\mathbf{R}^{\mathbf{2}}$ & hCA-II & $\mathbf{R}^{\mathbf{2}}$ & $\mathbf{A C h E}$ & $\mathbf{R}^{\mathbf{2}}$ \\
\hline Çuha Çiçeği Yağı & 0,1950 & 0,9414 & 0,1406 & 0,8589 & 0,1097 & 0,9549 \\
\hline Tatlı Badem Yağı & 0,0345 & 0,9718 & 0,0266 & 0,9769 & 0,0394 & 0,8420 \\
\hline
\end{tabular}
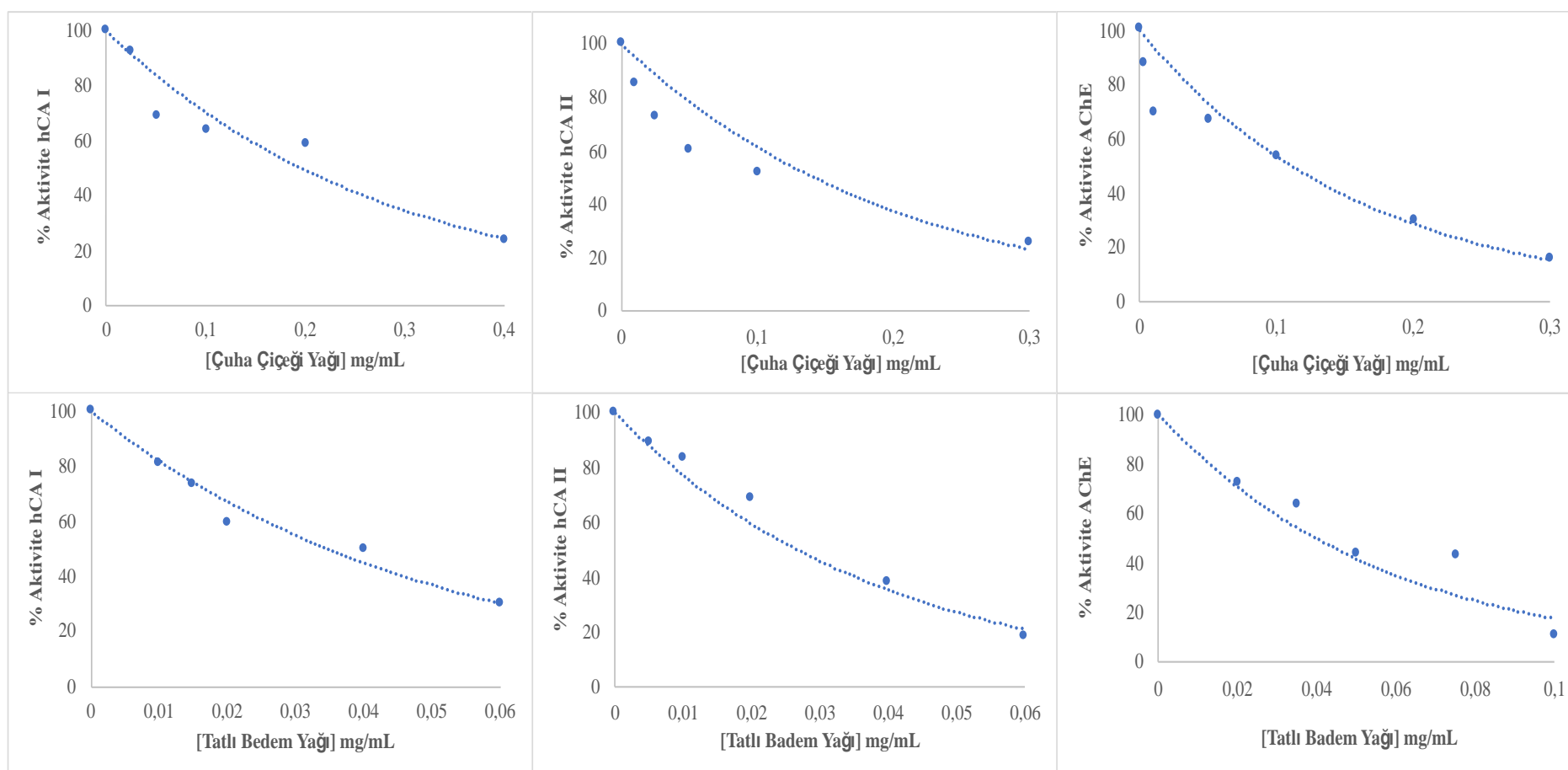

Şekil 1. Çuha Çiçeği ve Tatlı Badem Yağının hCA I-II ve AChE Enzim Aktiviteleri Üzerindeki Etkilieri

Literatüre baktığımızda bitki ekstrelerinin enzimlerin aktiviteleri üzerindeki etkilerinin araştıııldığı birçok çalışma olduğu görülmektedir (Oluba et al., 2007; Bangou, 2011; Sacan ve Yildiz, 2014; El-Hadary ve Ramadan, 2019). Dahası karbonik anhidraz enzim aktivitesi üzerine siyah, beyaz ve bitkisel çayların, tarhunun, çakşır'ın, çiriş'in, 1şkının, eşek çakşır'ının, cefan kavun çekirdek ekstresinin inhibisyon etkileri araştırılmıştır (Yurtvermez, 2016; Sevim, 2018; Akkemik 2019). Çuha çiçeği yağının hCA I ve hCA II enzim aktivitelerindeki $\mathrm{IC}_{50}$ değerleri sırasıyla 0,1950 ve $\mathrm{IC}_{50} 0,1406 \mathrm{mg} / \mathrm{mL}$ olarak tespit edildi (Şekil 1, Tablo 2). Çuha çiçeğinin hCA II enzim aktivitesi üzerinde daha yüksek bir inhibisyon göstermesinin yanı sıra iki izoenzim üzerinde de yakın bir inhibisyon sergilediği ve Çuha çiçeği yağının karbonik anhidrazın söz konusu iki izoenzimi için seçimli bir inhibisyon etkisi göstermediği tespit edildi. 
Tatlıbadem yağının hCA I ve hCA II enzim aktivitelerindeki IC $_{50}$ değerleri sırasıyla 0,0345 ve $0,0266 \mathrm{mg} / \mathrm{mL}$ olarak tespit edildi (Şekil 1, Tablo 2). Tatlıbadem yağının hCA II enzim aktivitesi üzerinde daha yüksek bir inhibisyon göstermesinin yanı sıra iki izoenzim üzerinde de yakın bir inhibisyon sergilediği belirledi. Ancak mikro seviyede bir inhibisyon etkisi göstermesi nedeniyle hCA I-II'nin sebep olduğu hastalıklarda tatı badem yağının tedavi etkisi olabileceği düşünülmektedir.

Yunan ve Romalı filozofların bıraktığı kaynaklar incelendiğinde Alzheimer hastalığının ilk tanısının konulduğu tarihten ziyade daha eskilere dayandığı belirtilmiştir (Berchtold ve Cotman 1998). Alzheimer hastalığı ile mücadele için hastalığın sebepleri araştırılmaktadır. Alzheimer hastalarını beyinlerinin neokorteks ve hipokampus bölgelerinin, b-amiloid plakların (Glenner ve Wong 1984a, Glenner ve Wong 1984b) hücre dışı birikintilerinden ve nörofibriler yumakların hücre içi birikintilerinden (Wiśniewski ve ark 1976; Goedert 1989) etkilendiği ifade edilmiştir (Hostettmann ve ark., 2006). Alzheimer hastalarının beyinlerinde kolinerjik kayıp, önemli kimyasalların dengesinin bozulması ve programlanandan daha önce belirgin şekilde hücre kayıplarının olmasını söyleyebiliriz (Drachman ve Leavitt, 1974; Perry ve ark., 1977; Whitehouse ve ark., 1982). Asetilkolin esteraz enziminin inhibitörlerinin (takrin, donepezil, rivastigmine ve galantamine) bu hastalığın tedavisinde kullanıldığı belirtilmektedir (Selkoe 1992; Schumock 1998; Grutzendler ve Morris 2001; Zarotsky ve ark., 2003). Asetilkolin esteraz enziminin inhibitörleri enzimin substratı olan asetilkolin yıkımını engelleyerek kolinerjik iletimini artırmaktadır (Sharma, 2019). Asetilkolin esteraz enziminin dönüşümlü ve dönüşümsüz inhibitörleri mevcuttur (Lin ve ark., 1998; Fulton ve Key 2001). Ancak enzimin dönüşümsüz inhibitörleri oldukça toksiktir (Fulton ve Key 2001; Costa 2006). Enzimin inhibitörlerinin Myastenia Gravis ve glokom hastalıklarında da kullanıldığı ifade edilmiştir (Quinn 1987; Rahman A and Choudhary 2001). Asetilkolin estereaz enziminin inhibitörlerinin çok sayıda yan etkisi olması ve istenen etkiyi tam olarak sergilememesi farklı inhibitörlerinin sentezlenmesine veya araştırılmasına neden olmuştur (Lin ve ark., 1998). Asetilkolinesteraz enziminin çok sayıda doğal kaynaklı inhibitörleri araştırılmıştır (Hostettmann ve ark., 2006). Bu inhibitörler içerisinde çay ağacı yağı, nane yağı, misket limonu yağı, melisa yağı ve adaçayı yağı gibi bazı esansiyel yağlarda vardır (Perry ve ark., 1996; Miyazawa ve ark., 1998; Perry ve ark., 2000; Mills ve ark., 2004; Hostettmann ve ark., 2006). Dahası Çuha çiçeğinin bitki ekstresininde AChE enzim aktivitesi üzerinde inhibisyon etkisi gösterdiği ve $\mathrm{IC}_{50}$ değerinin $20,09 \mu \mathrm{g} / \mathrm{mL}$ olduğu ifade edilmiştir (Lee ve ark., 2017). Çuha çiçeğinin bitki ekstresinin yağ ekstresine ( $\left.\mathrm{IC}_{50} 0,1097 \mathrm{mg} / \mathrm{mL}\right)$ göre daha yüksek bir inhibisyon etkisi gösterdiği literatürdeki veri kıyaslanarak söylenebilir.

Bu çalışmada Çuha çiçeği ve tatı badem yağlarının asetilkolin estereaz enziminin aktivitesi üzerindeki etkilerini in vitro şartlarda araştırıldı. Elde edilen verilere göre tatlı badem yağ $\left(\mathrm{IC}_{50} 0,0394 \mathrm{mg} / \mathrm{mL}\right)$, çuha çiçeği yağına $\left(\mathrm{IC}_{50} 0,1097 \mathrm{mg} / \mathrm{mL}\right)$ göre AChE enzim aktivitesi üzerinde daha etkili bir inhibisyon etkisi gösterdi. Bu çalışma neticesinde erken tanı veya orta seviye Alzheimer hastalığı tedavisinde yan etkileri olan sentetik ilaçlar yerine tatlı badem yağının klinik öncesi ve sonrası çalışmaları tamamlanarak doğal ilaç olarak kullanılabileceği düşünülmektedir.

\section{Sonuç}

Karbonik anhidraz ve asetilkolinesteraz enziminin inhibitörleri birçok hastalıkta ilaç olarak kullanılmaktadır. Ancak mevcut inhibitörlerin çok sayıda yan etkilerinin olması ya da her hastada istenen etkiyi göstermemesi nedeniyle belirtilen enzimlerin inhibitörleri gerek sentezlenerek gerekse doğal bitki ekstreleri kullanılarak araştırılmaya devam etmektedir (Bangou ve ark. 2011; Aksu ve ark., 2016; Gülçin ve ark., 2016; Adem ve ark., 2019; Akkemik ve ark., 2019). Bu çalışmada ilk kez çuha çiçeği (Oenothera biennis) yağı'nın karbonik anhidraz I-II ve asetilkolin esteraz enzim aktivitesi üzerindeki ( IC $_{50} 0,1950,0,1406$ ve $0,1097 \mathrm{mg} / \mathrm{mL}$ ) etkileri in vitro şartlarda araştırıdı. Çuha çiçeği (Oenothera biennis) yağı'nın söz konusu enzimler üzerinde yakın bir inhibisyon etkisi gösterdiği tespit edildi. Tatlı badem (Prunus dulcis Mill.) yağının karbonik anhidraz I-II ve asetilkolin esteraz enzim aktivitesi üzerindeki IC $_{50}$ değerleri ise sırasıyla $0,0345,0,0266$ ve $0,0394 \mathrm{mg} / \mathrm{mL}$ olarak belirlendi. Çalışmada kullanılan her iki yağ karşılaştırıldığında tatlı badem (Prunus dulcis Mill.) yağının $\mathrm{IC}_{50}$ değerinin mikro seviyede olması nedeniyle, her iki enzim aktivitesi üzerinde daha etkili olduğu ortaya çıktı. Bu nedenle sentetik ilaçlar yerine tatı badem (Prunus dulcis Mill.) yağının söz konusu enzimlerin sebep olduğu hastalıkların tedavisinde takviye ilaç olarak kullanılabileceği düşünülmektedir.

\section{Kaynakça}

Adem, S., Akkemik, E., Aksit, H., Guller, P., Tüfekci, A.R., Demirtas, İ., Ciftci, M. (2019). Activation and inhibition effects of some natural products on human cytosolic CAI and CAII. Medicinal Chemistry Research, 28:711-722.

Aggarwal, M., Kondeti, B., McKenna, R. (2013). Insights Towards Sulfonamide Drug Specificity in A-Carbonic Anhydrases. Bioorganic \& Medicinal Chemistry, 21(6): 1526-1533.

Ahmad, Z. (2010). The uses and properties of almond oil. Complementary Therapies in Clinical Practice, 16(1), 10-12 4.

Akalın, Ş. (1952). Büyük bitkiler kılavuzu. Cilt 1, Güzel Sanatlar Matbaası, 628s Ankara.

Akıncıŏglu A, Akıncıoğlu H, Gül.in I, Durdağı, S., Supuran, C.T., Göksu, S. (2015). Discovery of potent carbonic anhydrase and acetylcholine esterase inhibitors: novel sulfamoylcarbamates and sulfamides derived from acetophenones. Bioorg Med Chem 23(13):3592-602

Akıncıŏglu, A., Topal, M., Gülçin, I., Göksu, S., (2014). Novel Sulphamides and Sulphonamides Incorporating the Tetralin Scaffold as Carbonic Anhydrase and Acetylcholine Esterase Inhibitors. Arch Pharm 347:1, 68-76.

Akkemik, E., Aybek, A., Felek, I. (2019). Effects of Cefan Melon (Cucumıs Melo L.) Seed Extracts on Human Erythrocyte Carbonıc Anhydrase I-II Enzymes. Applied Ecology And Environmental Research, 17(6):14699-14713.

Akkemik, E., Cicek, B., Camadan, Y., Calisir, U., Onbasioglu, Z. (2018). The determination of the carbonic anhydrase's activators in vitro effect of mixed donor crown ethers. Journal of Biochemical and Molecular Toxicology, 32(3): e22032.

Akkemik, E., Çalışır, Ü., Çiçek, B. (2017). İnsan karbonik anhidraz I,II izoenzim aktiviteleri üzerine bazı tiyocrown eterlerin etkisi. J. BAUN Inst. Sci. Technol, 19(2), 192-199. 
Aksu, K., Özgeriş, B., Taslimi, P., Naderi, A., Gülçin, I., Göksu, S. (2016). Antioxidant Activity, Acetylcholinesterase, and Carbonic Anhydrase Inhibitory Properties of Novel Ureas Derived from Phenethylamines.Arch Pharm 349(12):944-954.

Ammar, N.M., Soroor, K.H.A., Mohammed, D.A. (2000). Impact of natural oils supplements on disease activity and antioxidant state of Egyptian patients with rheumatoid arthritis. MJIAS; 13: 161-171.

Anonim, (2020). https://www.pfizer.com.tr/arge/yeni-ila\%C3\%A7-geli\%C5\%9Ftirme-s\%C3\%BCreci, 14.02.2020, 18:36

Balta, M.F. (2013). Fatty acid profiles for almond [Prunus amydalus Batsch] genotypes with different kernel taste and formation. Iğdır Univ. J. Inst. Sci. Tech, 3(1), 17-24. 3.

Bangou, J. M., Kiendrebeogo, M., Compaore, M., Coulibaly, A. Y., Roland Meda, N. T., Abarka Almaraz, N., Zeba, B., MillogoRasolodimby, J., Nacoulma, O.G. (2011). Enzyme inhibiting effect and polphenolic content of medicinal plant extracts from Burkina Faso. Journal of Biological Sciences, 11(1): 31-38.

Bayrak, S., Yılmaz, Ö. (2009). Ceviz- Badem yetiştiriciliği. Rekmay Reklam ve Tanıtım Ltd. Şti., 321s Ankara.

Berchtold, N. C., and Cotman. C.W. (1998). Evolution in the conceptualization of dementia and Alzheimer's disease: Greco-Roman period to the 1960s. Neurobiol Aging 19(3) 173-189,

Bıçakcı, Z. (2015). Acute Hepatitis-A Infection Induced Anemia in Concurrence of Glucose-6-Phosphate Dehydrogenase Deficiency and Thalassemia Trait: A Case Report, Kafkas J Med Sci Kafkas J Med Sci 2015; 5(1):31-35.

Birch, A.E., Fenner, G.P., Watkins, R., Boyd, L.C. (2001). Antioxidant properties of evening primrose seed extracts. J Agric Food Chem, 49: 4502-s4507.

Boztaş, M., Çetinkaya, Y., Topal, M., Gülçin, I., Menzek, A., Şahin, E., Tanc, M., Supuran, C.T. (2015). Synthesis and carbonic anhydrase isoenzymes I, II, IX, and XII inhibitory effects of dimethoxybromophenol derivatives incorporating cyclopropane moieties. J Med Chem 58 (2), 640-650.

Bradford, M.M. (1976). A rapid and sensitive method for the quantitation of microgram quantities of protein utilizing the principle of protein-dye binding. Anal Biochem 72:248-54

Chen, C.Y., Lapsley, K., Blumberg, J. (2006). A nutrition and health perspective on almond. J. Sci. Food Agric. 86, $2245-2250$.

Costa, L.G. (2006). Current issues in organophosphate toxicology. Clinica Chimica Acta, 366, 1-13.

Darvesh, S., Darvesh, K.V., McDonald, R.S., Mataija, D., Walsh, R., Mothana, S., Lockridge, O., Martin, E. (2008). Carbamates with differential mechanism of inhibition toward acetylcholinesterase and butyrylcholinesterase. J Med Chem, 51(14):4200-12.

Davis, P.A., Iwahashi, C.K. (2001). Whole almonds and almond fractions reduce aberrant crypt foci in a rat model of colon carcinogenesis. Cancer. Lett, 165(1):27-33

Drachman, D.A., Leavitt, J. (1974). Human Memory and the Cholinergic System A Relationship to Aging? Arch Neurol. 30(2):113121

El-Hadary, A.E., Ramadan, M.F. (2019). Phenolic profiles, antihyperglycemic, antihyperlipidemic, and antioxidant properties of pomegranate (Punica granatum) peel extract. Journal of Food Biochemistry, e12803.

Ellman, G.L., Courtney, K.D., Andres, V., Featherston, R.M. (1961). A new and rapid colorimetric determination of acetylcholinesterase activity, Biochem Pharmacol 7:88-95.

Favati, F., King, J.W., Mazzati, M. (1991). Supercritical carbon dioxide extraction of evening primrose oil. JAOCS, 68: $422-427$.

Fulton, M.H., and Key, P.B. (2001). Acetylcholinesterase Inhiıbition In Estuarine Fish and Invertebrates As an Indicator of Organophosphorus Insecticide Exposure and Effects, Environmental Toxicology And Chemistry, 20:1, Pp. 37-45,

Glenner, G.G., Wong, C.W. (1984a). Alzheimer's disease: initial report of the purification and characterization of a novel cerebrovascular amyloid protein. Biochem Biophys Res Commun, May 16;120(3):885-90.

Glenner, G.G., Wong, C.W. (1984b). Alzheimer's disease and Down's syndrome: sharing of a unique cerebrovascular amyloid fibril protein. Biochem Biophys Res Commun. Aug 16;122(3):1131-5.

Goedert, M., Spillantini, M.G., Jakes, R., Rutherford, D., Crowther, R.A. (1989). Multiple isoforms of human microtubule-associated protein tau: sequences and localization in neurofibrillary tangles of Alzheimer's disease. Neuron. Oct;3(4):519-26.

Gokcen, T., Topal, M., Gulcin, I., Ozturk, T., Goren, A.C. (2017). Synthesis of some natural sulphonamide derivatives as carbonic anhydrase inhibitors. Org Commun, 10:15-23

Göksu, H., Topal, M., Keskin, A., Gültekin, M.S., Çelik, M., Gülçin, I., Tanc, M., Supuran, C.T. (2016). 9,10-Dibromo-N-aryl-9,10dihydro-9,10-[3,4]epipyrroloanthracene-12,14-diones: Synthesis and Investigation of Their Effects on Carbonic Anhydrase Isozymes I, II, IX, and XII. Arch Pharm, 349(6):466-74.

Grutzendler, J., Morris, J.C. (2001). Cholinesterase inhibitors for Alzheimer's disease. Drugs, 61(1):41-52.

Gul, H.I., Demirtas, A., Ucar, G., Taslimi, P., Gülçin, I. (2017a). Synthesis and biological evaluation of aminomethyl and alkoxymethyl derivatives as carbonic anhydrase, acetylcholinesterase and butyrylcholinesterase inhibitors, Lett Drug Des Discov, 32(1): 11741182.

Gul, H.I., Mete, E., Taslimi, P., Gulcin, I., Supuran, C.T. (2017b). Synthesis, carbonic anhydrase I and II inhibition studies of the 1,3,5trisubstituted-pyrazolines, J Enzym Inhib Med Chem, 32:1, 189-192.

Gülçin, I., Scozzafava, A., Supuran, C.T, Akıncıŏlu, A., Köksal, Z., Türkan, F., Alwasel, S. (2016). Rosmarinic acid inhibits some metabolic enzymes including glutathione S-transferase, lactoperoxidase, acetylcholinesterase, butyrylcholinesterase and carbonic anhydrase isoenzymes. Journal of Enzyme Inhibition and Medicinal Chemistry, 31: 1698-1702

Habtemariam, S. (2019). Natural Products in Alzheimer's Disease Therapy: Would Old Therapeutic Approaches Fix the Broken Promise of Modern Medicines?. Molecules, 24, 1519;

Hederos, C.A., Berg, A. (1996). Epogam evening primrose oil treatment in atopic dermatitis and asthma. Arch Dis Child, 75: $494-497$.

Hostettmann, K., Borloz, A., Urbain, A., and Marston, A. (2006). Natural Product Inhibitors of Acetylcholinesterase, Current Organic Chemistry, 10, 825-847 
Hyson, D.A., Schneeman, B.O., Davis, P.A. (2002). Almonds and almond oil have similar effects on plasma lipids and LDL oxidation in healthy men and women. J Nutr, 132(4):703-7. 8.

Ismail, M.F., EL-Maraghy, S.A., Sadik, N.A.H. (2008). Study of the immunomodulatory and anti- inflammatory effects of evening primrose oil in adjuvant arthritis. AJBR, 2: 74- 80.

Jenkins, D.J., Kendall, C.W., Josse, A.R., Salvatore, S., Brighenti, F., Augustin, L.S. (2006). Almonds decrease postprandial glycemia, insulinemia, and oxidative damage in healthy individuals. J. Nutr, 136, 2987-2992.

Jenkins, D.J., Kendall, C.W., Marchie, A., Parker, T.L., Connelly, P.W., Qian, W., et al. (2002). Dose response of almonds on coronary heart disease risk factors: blood lipids, oxidized low-density lipoproteins, lipoprotein a, homocysteine, and pulmonary nitric oxide: a randomized, controlled, crossover trial. Circulation, 106(11):1327-32. 9.

Jennifer, M., Moody, W., Heywood, J.S. (2001). Pollination limitation to reproductive success in the missouri evening primrose, Oenothera Macrocarpa (Onagraceae). Am J Bot; 88: 1615-1622.

Kaya, Z. (2010). Arsenikle Lipid Peroksidasyon Oluşturulan Ratlarda Çuha Çiçeği Yağının Etkileri Farmakoloji-Toksikoloji Anabilim Dalı, Yüksek Lisans Tezi, Kayseri Erciyes Üniversitesi, Sağlık Bilimleri Enstitüsü, 45p, Kayseri

Kocyigit, U.M., Budak Y., Gürdere, M.G., Dürü, N., Taslimi, P.,· Gülçin, İ., Ceylan, M. (2019). Synthesis and investigation of anticancer, antibacterial activities and carbonic anhydrase, acetylcholinesterase inhibition profiles of novel ( $3 \mathrm{a}$ R, 4S ,7 R ,7a S )-2 -[4 -[1 -ac ety 1-5 -(a ryl /he ter oar yl) -4, 5- d ihy dro -1 H- pyr azo 1-3 -yl ]ph eny 1]- 3a, 4,7 ,7a -te tra hyd ro- 1H -4,7methanoisoindole-1,3(2H)-diones, Monatsh. Chem. 150:721-731.

Krasavin, M., Korsakov, M., Zvonaryova, Z., Semyonychev, E., Tuccinardi, T., Kalinin, S., Tanç, M., Supuran, C.T. (2017). Human carbonic anhydrase inhibitory profile of mono- and bis-sulfonamides synthesized via a direct sulfochlorination of 3- and 4-(hetero) arylisoxazol-5-amine scaffold Bioorg Med Chem 25(6):1914-1925

Laemmli, U.K. (1970). Cleavage of structural proteins during the assembly of the head of bacteriophage T4. Nature 227, 680-5.

Lee, S., Lee, D., Baek, J Jung, E.B., Baekb, J.Y., Leec, I.K., Jangd, T.S., Kangb, K.S., Kima K.H. (2017). In Vitro Assessment Of Selected Korean Plants For Antioxidant And Antiacetylcholinesterase Activities, Pharmaceutical Biology, VOL. 55, NO. 1, 22052210

Lin, G., Tsai, Y.C., Liu, H.C., Liao, W.C., Chang, C.H. (1998). Chang Enantiomeric inhibitors of cholesterol esterase and acetylcholinesterase, Biochimica et Biophysica Acta, 1388 161-174

Mills, C., Cleary, B. V., Walsh, J.J., Gilmer, J.F. (2004). Inhibition of acetylcholinesterase by Tea Tree oil. Journal of Pharmacy and Pharmacology, 56:3, 375-379

Miyazawa, M., Yoshio, K., Ishikawa, Y., Kameoka, H. (1998). Insecticidal Alkaloids against Drosophila melanogaster from Nuphar japonicum DC. J. Agric. Food Chem. 46, 1059-1063.

NTP. (2009). İnformation review document for evening primrose oil (Oenotherabiensis L.), CAS No: 90028-66-3, 1-37.

Oluba, O., Adeyemi, O., Ojieh, G., Isiosio, I. (2007). Fatty acid composition of Citrullus lanatus (Egusi melon) oil and its effect on serum lipids and some serum enzymes. The Internet Journal of Cardiovascular Research, 5(2): 1-7.

Özaslan, E., Sivri B. (1998). Makroenzimler ve Makroamilazami, Güncel Gastroenteroloji, 2:2, 163-169.

Perry, E.K., Gibson, P.H., Blessed, G., Perry, R.H., Tomlinson, B.E. (1977). Neurotransmitter enzyme abnormalities in senile dementia: Choline acetyltransferase and glutamic acid decarboxylase activities in necropsy brain tissue, Journal of the Neurological Sciences, $34: 2,247-265$.

Perry, N., Court, G., Bidet, N., Court, J., Perry, E. (1996). European Herbs with Cholinergic Activities: Potential in Dementia Therapy, International Journal of Geriatric Psychiatry, 11: 1063-1069

Perry, N.S.L., Houghton, P.J., Theobald, A., Jenner, P., Perry, E.K. (2000). In-Vitro Inhibition of Human Erythrocyte Acetylcholinesterase Bysalvia Lavandulaef oli essential Oil and Constituent Terpenes. Journal of Pharmacy and Pharmacology, 52(7), 895-902.

Polat, K.L., Gülçin, I., Gören, A.C., Namiesnik, J., Martinez-Ayala, A.L., Gorinstein, S. (2015). LC-MS/MS analysis, antioxidant and anticholinergic properties of galanga (Alpinia officinarum Hance) rhizomes. Ind Crops Prod, 74: 712-721

Quinn, D.M. (1987). Acetylcholinesterase: Enzyme Structure, Reaction Dynamics, and Virtual Transition States, Ct”. Rev. 87. 955979.

Rahman, A., Choudhary, M.I. (2001). Bioactive natural products as a potential source of new pharmacophores. A theory of memory, Pure Appl. Chem., 73:3, pp. 555-560,

Riaz, A., Khan, R.A., Ahmed, S.P. (2009). Assessment of anticoagulant effect of evening primrose oil. Pak J Pharm Sci, 22: $355-359$.

Ronceroa, J.M., Álvarez-Ortí, M., Pardo-Giménez, A., Gómez, R., Rabadán, A., Pardo, J.E., (2016). Virgin almond oil: Extraction methods and composition. Grasas Aceites, 67:(3): e143.

Sacan, O., Yildiz, E. (2014). Turhan, lipoxygenase inhibitory activities of some plant extracts and chemical compounds. The Journal of Biological Chemistry, 73(2): 47-52.

Santos, T.C., Gomes, T.M., Pinto, B.A.S., Camara, A.L., Andrade Paes, A.M. (2018). Naturally Occurring Acetylcholinesterase Inhibitors and Their Potential Use for Alzheimer's Disease Therapy, Frontiers in Pharmacology, 9, 1192

Schumock, G.T. (1998). Economic considerations in the treatment and management of Alzheimer's disease. Am J Health-Syst Pharm. 55(suppl 2):S17-21.

Scozzafava, A., Mastrolorenzo, A., Supuran, C. T. (2006). Carbonic anhydrase inhibitors and activators and their use in therapy. Expert Opinion on Therapeutic Patents 16(12): 1627-1664.

Selkoe, D.J. (1992). Aging brain, aging mind. Sci Am. 267(3):134-42.

Sevim, O. (2018): Determination of some macro and micro element contents of multi-medical plants growed in agri and the effects of these elements on metabolic enzyme. Ağrı İbrahim Çeçen Üniversitesi, Fen Bilimleri Enstitüsü, Kimya Anabilim Dalı, Yüksek Lisans Tezi, Ağrı, Türkiye. 
Sharma, K. (2019). Cholinesterase inhibitors as Alzheimer's therapeutics (Review), Molecular Medicine REPORTS 20: 1479-1487.

Smirnoviené, J., Smirnovas, V., Matulis, D. (2017). Picomolar inhibitors of carbonic anhydrase: Importance of inhibition and binding assays. Anal Biochem, 522:61-72.

Spiller, G.A., Jenkins, D.A., Bosello, O., Gates, J.E., Cragen, L., Bruce, B. (1998). Nuts and plasma lipids: an almond-based diet lowers LDL-C while preserving HDL-C. J. Am. Coll Nutr. 17, 285-290.

Sultana, Y., Kohli, K., Athar, M., Khar, R.K., Aqil, M. (2007). Effect of pre-treatment of almond oil on ultraviolet B-induced cutaneous photoaging in mice. Journal of cosmetic dermatology, 6(1), 14-19. 10.

Supuran, C.T. (2007). Curr Top Med Chem 7:825

Supuran, C.T. (2008). Carbonic anhydrases as drug targets. Current Pharmaceutical Design, 14(7): 601-2.

Tarawneh, R., Holtzman, D. M. (2012). The clinical problem of symptomatic Alzheimer disease and mild cognitive impairment. Cold SpringHarbor Perspect. Med. 2:a006148.

Taslimi, P., Gülçin, I., Özgeriş, B., Göksu, S., Tümer, F., Alwasel, S.H., Supuran, C.T. (2016b). The human carbonic anhydrase isoenzymes I and II (hCA I and II) inhibition effects of trimethoxyindane derivatives, J Enzym Inhib Med Chem, 31:4, 152-157.

Taslimi, P., Gülçin, I., Öztaşkın, N., Çetinkaya, Y., Göksu, S., Alwasel, S.H., Supuran, C.T. (2016a). The effects of some bromophenols on human carbonic anhydrase isoenzymes, J Enzym Inhib Med Chem, 31:4- 603-607.

Topal, F., Gulcin, I., Dastan, A., Guney, M. (2017). Novel eugenol derivatives: Potent acetylcholinesterase and carbonic anhydrase inhibitors. Int J Biol Macromol, 94, 845-851.

Verpoorte, J., Mehta, S., Edsall, J.T. (1967). Esterase activities of human carbonic anhydrases B and C. The Journal of Biological Chemistry, 242, 4221-4229,

Vullo, D., Del Prete, S., Nocentini, A., Osman, S.M., Al Othman, Z., Capasso, C., Bozdag, M., Carta, F., Gratteri, P., Supuran, C.T. (2017). Dithiocarbamates effectively inhibit the $\beta$-carbonic anhydrase from the dandruff-producing fungus Malassezia globosa, Bioorg Med Chem 25:3; 1260-1265

Whitehouse, P.J., Price, D.L., Struble, R.G., Clark, A.W., Coyle, J.T., Delon, M.R. (1982). Alzheimer's disease and senile dementia: loss of neurons in the basal forebrain, Science 215 (4537), 1237-1239

Wiśniewski, H.M., Narang, H.K., Terry, R.D. (1976). Neurofibrillary tangles of paired helical filaments. J Neurol Sci., 27(2):173-81.

Yurtvermez, B. (2016). Isolation of bioactive secondary metabolites from tarragon (Artemisia dracunculus L.) and identification of their chemical structures. Ağnı İbrahim Çeçen Üniversitesi, Fen Bilimleri Enstitüsü, Kimya Anabilim Dalı, Yüksek Lisans Tezi, Ağrı, Türkiye.

Zarotsky, V., Sramek, J.J., Cutler, N.R. (2003). Galantamine hydrobromide: An agent for Alzheimer's disease, Am J Health-Syst Pharm-Vol 60:1,

Zohary, D., Hopf, M. (2001). Domestication of plants in the old world. 3rd ed. London: Oxford University Press; 2000. p. 186. 6. 